\title{
Cadherin-catenin adhesion system and mucin expression: a comparison between young and older patients with gastric carcinoma
}

\author{
Edaise M. Silva ${ }^{1}$, Maria D. Begnami ${ }^{1}$, José Humberto T.G. Fregnani ${ }^{2}$, Adriane G. Pelosof ${ }^{3}$, Claudia Zitron ${ }^{3}$, \\ André L. Montagnini ${ }^{4}$, and Fernando Augusto Soares ${ }^{1}$ \\ ${ }^{1}$ Department of Anatomic Pathology, Hospital AC Camargo, Rua Antonio Prudente, 109 - ${ }^{\circ}$ Andar, São Paulo 01509-010, Brazil \\ ${ }^{2}$ Department of Morphology, Medical School of Santa Casa of São Paulo, São Paulo, Brazil \\ ${ }^{3}$ Endoscopy Service, Hospital AC Camargo, São Paulo, Brazil \\ ${ }^{4}$ Department of Abdominal Surgery, Hospital AC Camargo, São Paulo, Brazil
}

\begin{abstract}
Background. Young patients are thought to develop gastric carcinomas with a molecular genetic profile that is distinct from that of gastric carcinomas occurring at a later age. The aim of this study was to compare the clinicopathological features and expression patterns of the markers E-cadherin and $\beta$-catenin, and mucins (MUC1, MUC2, MUC5AC, and MUC6) in young and older patients.

Methods. The clinicopathological features and overall survival data of 62 young patients (age $\leq 40$ years) with gastric cancer were retrospectively reviewed from hospital records and compared with the data for 453 older patients (age $>40$ years). A tissue microarray method and immunohistochemistry were used in order to analyze marker expression in paraffinembedded tissue blocks obtained from both groups.

Results. The young group presented a higher percentage of diffuse-type tumors in comparison to the older group $(P<$ $0.01)$. The rates of positivity for $E$-cadherin and $\beta$-catenin membranous expression patterns and mucin (MUC2, MUC5AC and MUC6) positivity were higher in the young group $(P<0.01)$. Although young patients showed a lower frequency of alterations in marker expression and had significantly better survival rates than the older patients, neither age nor the marker expression pattern were found to be independent prognostic factors of survival. Only stage, tumor size, and tumor location persisted as prognostic factors for patients with gastric cancer.

Conclusion. Biological markers of cellular adhesion and gastric differentiation were differently expressed in young and older patients. Our findings support the hypothesis that young patients develop carcinomas with a different genetic pathway compared to the pathway of tumors occurring at a later age, and we suggest further investigations to assess the prognostic relevance of the markers to specific subgroups.
\end{abstract}

Key words Gastric cancer · Young · E-cadherin · $\beta$-Catenin · Mucins · Tissue microarray

Offprint requests to: E.M. Silva

Received: December 14, 2007 / Accepted: May 5, 2008

\section{Introduction}

Gastric cancer is thought to involve a combination of environmental factors and an accumulation of specific genetic alterations, which lead to the progressive disturbance of cell growth and differentiation control. The disease occurs predominantly in older patients, with a peak of incidence in patients who are more than 60 years old [1-3].

Several studies have addressed the characteristics of this neoplasia in young patients, suggesting the clinicopathological and biological characteristics in young patients differ in many ways from gastric carcinoma in older patients. For young patients, the male:female ratio is approximately equal [3] or shows female predominance $[4,5]$, and the tumors are usually poorly differentiated, diffuse-type or infiltrative carcinomas [6-8]. Some authors have suggested that young patients have a worse prognosis, mainly due to the delay in diagnosis and more aggressive tumor behavior $[6,7,9$, 10], whereas others have shown no difference in survival between young and older patients [11, 12]. Also, young patients are thought to develop carcinomas with a molecular genetic profile that is distinct from that of sporadic carcinomas occurring at a later age [13-15].

A better understanding of the molecular differences between gastric carcinomas affecting young and old patients would allow us to investigate specific molecular biomarkers that could be involved in early gastric carcinogenesis, and the identification of such markers could then improve early diagnosis for specific groups.

Several studies have shown considerable interest in the influence of cell adhesion molecules such as Ecadherin and $\beta$-catenin, and also the mucins, in the development and progression of gastric tumors. Previous results from our group showed, through gene expression analyses using cDNA microarrays, that a large series of genes, including E-cadherin and MUC6 
gene expression, were differently expressed in gastric carcinomas [16].

E-cadherin is a transmembrane calcium-dependent cell adhesion molecule which plays an important role in the maintenance of intercellular adhesion, cell polarity, and mucosal architecture $[17,18]$. Functional cadherindependent cell adhesion requires the formation of complexes between E-cadherin and cytoplasmic proteins known as the catenins (e.g., $\beta$-catenin). $\beta$-Catenin is a multifunctional protein which plays an important role in Wingless/Wnt signaling transduction, in addition to its function as a cell-adhesion molecule [19]. Nuclear $\beta$-catenin expression was correlated with poor prognosis in several malignances [20]. Impairment of one or more components of this complex is associated with poor differentiation, dysfunction of intercellular adhesion, increased invasiveness of carcinomas [18, 21], and tumor progression and metastasis [22]. E-cadherin (CDH1) gene mutations have been associated with familial gastric cancer [23-27]. Not only E-cadherin gene alterations but also structural abnormalities and/or catenin dysfunction cause disruption of the E-cadherinmediated cell adhesion system [19].

Mucins are the major component of the mucous gel that covers the surface of epithelial tissue, and at least 13 mucins have been found [28]. It has been suggested that alterations in mucin expression may contribute to cancer invasion and metastatic capabilities through changes in cancer-cell growth regulation, immune recognition, and cellular adhesion [29-31]. The process of neoplastic transformation in the stomach has been reported to be associated with the decreased expression of mucins that are normally expressed in gastric mucosa (including MUC1, MUC5AC, and MUC6) and with the de novo expression of mucins (e.g., MUC2) that are normally expressed in other organs $[32,33]$.

The present study represents a retrospective analysis of patients with gastric carcinoma, carried out in order to compare the clinicopathological features and overall survival between two groups of patients divided by age ( $\leq 40$ and $>40$ years of age) and analyze whether differences exist between young and older patients in the expression of markers considered to be important in conventional gastric carcinogenesis, such as E-cadherin, $\beta$-catenin, and the mucins MUC1, MUC2, MUC5AC, and MUC6.

\section{Patients, materials, and methods}

\section{Patients}

This was a retrospective study of the tumor registry of patients who were admitted to the Hospital AC Camargo (São Paulo, Brazil) for the management of adenocarci- noma of the stomach between 1988 and 2005. A total of 515 patients were identified during the study period, and the clinicopathological features of these patients, including information on each patient's age, sex, tumor size, tumor location, histological tumor type, nodal involvement, and stage were reviewed. Tumor size was categorized according the mean size of all tumors $(\leq 5 \mathrm{~cm}$ and $>5 \mathrm{~cm}$ ) and tumor location was categorized as being in proximal or distal regions. Histologically, tumors were classified into three main groups: intestinal-type, diffuse-type, and mixed/unclassified-type gastric adenocarcinomas, according to the Laurén histological classification [34]. Pathological stage was classified according to the International Union Against Cancer (UICC) tumor-node-metastasis system (TNM) and it was categorized as early (stages I and II) and advanced (stages III and IV) for statistical analyses. The follow-up data were obtained from the hospital records. Overall survival was defined as the time elapsed between primary treatment and death from gastric cancer or from other causes.

\section{Tissue microarray method and immunohistochemistry}

Formalin-fixed, paraffin wax-embedded tissues from 515 gastric carcinomas were retrieved from the archival tissue bank of the Department of Anatomic Pathology. A section from each specimen was stained with hematoxylin and eosin (H\&E) for histological evaluation and the selection of morphologically representative sites in the tumors to construct tissue microarray (TMA) blocks. Our series included 470 cases from TMA blocks (including 17 cases from young patients) and another 45 cases analyzed in conventional sections (including 6 tumorderived biopsies from young patients). For TMA block construction, tissue core biopsies (diameter, $0.6 \mathrm{~mm}$ ) were punched from selected regions of donor paraffinembedded tumor blocks and precisely arrayed into a new recipient paraffin block, using a precision instrument (Beecher Instruments, Silver Spring, MD, USA). Published studies on TMAs have reported the comparability of immunohistochemical results from TMAs versus corresponding large sections [35, 36]. These studies found that the analysis of two cores provided representative information, as compared with the corresponding whole-tissue section. In the present study, all the cases were spotted twice in each TMA block and immunohistochemistry was carried out in two slides at different depth levels, to increase the accuracy and the strength of the array-based data. Immunohistochemical analysis was performed in $3-\mu \mathrm{m}$-thick sections from each sample of TMA block and conventional blocks by the standard streptavidin-biotin peroxidase technique. Briefly, tissue sections were deparaffinized and rehydrated, and antigen retrieval was performed by placing 
the tissue sections in citrate buffer (0.01 M, pH 6.0) in a pressure cooker. Endogenous peroxidase was blocked using 3\% hydrogen peroxide and then the sections were washed with phosphate-buffered saline (PBS), $\mathrm{pH}$ 7.4. The sections were incubated with a primary mouse monoclonal antibody overnight at $4{ }^{\circ} \mathrm{C}$ : E-cadherin (1: 750; BD Transduction, San Jose, CA, USA); $\beta$ catenin (1: 1000; BD Transduction); all mucins, by Novocastra (New Castle, UK); MUC1 [1: 500], MUC2 [1: 1000], MUC5AC [1: 500], and MUC6 [1: 600]). Then, the sections were incubated for $30 \mathrm{~min}$ at room temperature with biotinylated secondary antibodies (K492; DAKO, Copenhagen, Denmark), followed by three washes in PBS and incubation with 3, 3-diaminobenzidine-tetrahydrochloride solution for $5 \mathrm{~min}$. The sections were counterstained with hematoxylin. For negative control preparations, the primary antibodies were omitted from the reaction sequence.

The expression of E-cadherin and $\beta$-catenin in malignant cells was compared with that in nonmalignant cells. Only a membranous pattern, which was stained as strongly as normal epithelial cells, was considered to be normal. In contrast, an absent pattern (loss of staining), a cytoplasmic pattern (cytoplasmic staining with loss of membranous expression), and a heterogeneous pattern (cytoplasmic staining with preservation of membranous expression) were categorized as altered patterns [21]. Nuclear staining of $\beta$-catenin was also categorized as an altered pattern. In the case of mixed patterns in some sections, the classification was based on the dominant pattern. The expression of the mucins MUC1, MUC2, MUC5AC, and MUC6 was considered positive if at least $10 \%$ of the neoplastic cells were stained [37].

\section{Statistical analysis}

All statistical analyses were performed using the SPSS 13.0 statistical software program (SPSS, Chicago, IL, USA). The $\chi^{2}$ test and Fisher's exact test were used to analyze the association between age and clinicopathological parameters and molecular biomarker expression. Five-year survival rates were estimated using the Kaplan-Meier method, and the log-rank test was used to compare the curves. The Cox proportional hazards model was performed to find the independent risk factors for death. For all tests, the alpha error was set at $5 \%$.

\section{Results}

A total of 515 patients with gastric adenocarcinomas were divided into two groups according to their age: young (age $\leq 40$ years; $n=62$ ) and older patients (age $>40$ years; $n=453$ ). Of the 62 young patients (mean age, 35 years), 38 (61.3\%) were 35 years old or younger, and $20(32.2 \%)$ were less than 30 years old.

Table 1 summarizes the clinicopathological findings of gastric carcinoma in the 515 patients divided by age ( $\leq 40$ years vs $>40$ years old). The young and older patients had similar distributions with respect to sex, tumor location, and stage $(P>0.05)$. There were some differences in distributions related to tumor size and lymph node metastasis, but the differences did not reach statistical significance. According to Laurén's histological classification [34], the young group had a significantly higher percentage of diffuse-type tumor than the older group $(P<0.01)$.

Representative immunohistochemistry staining for marker expression pattern in the gastric cancer can be seen in Figs. 1-3. As shown in Table 2, alterations in the E-cadherin/ $\beta$-catenin adhesion complex patterns occurred in a high percentage of gastric carcinomas in both groups of patients: $73 \%$ of all evaluated samples presented are altered E-cadherin (absent/reduced) expression pattern, and $91 \%$ of all samples showed an altered $\beta$-catenin expression pattern. The rate of Ecadherin preserved membranous expression was higher

Table 1. Comparison of clinicopathological characteristics between young and older patients with gastric carcinoma

\begin{tabular}{|c|c|c|c|c|}
\hline Variable & Category & $\leq 40$ Years $n=62(\%)$ & $>40$ Years $n=453(\%)$ & $P$ value \\
\hline \multirow[t]{2}{*}{ Sex } & M & $38(61.3)$ & $288(63.6)$ & 0.73 \\
\hline & $\mathrm{F}$ & $24(38.7)$ & $165(36.4)$ & \\
\hline \multirow[t]{2}{*}{ Tumor location } & Proximal & $9(15.3)$ & $68(15.0)$ & 0.96 \\
\hline & Distal & $50(84.7)$ & $385(85.0)$ & \\
\hline \multirow[t]{2}{*}{ Tumor size } & $\leq 5 \mathrm{~cm}$ & $31(53.4)$ & $179(40.9)$ & 0.07 \\
\hline & $>5 \mathrm{~cm}$ & $27(46.6)$ & $259(59.1)$ & \\
\hline \multirow[t]{3}{*}{ Histological type } & Intestinal & $15(24.2)$ & $230(50.8)$ & $<0.01$ \\
\hline & Diffuse & $36(58.1)$ & $146(32.2)$ & \\
\hline & Mixed/unclassified & $11(17.7)$ & $77(17.0)$ & \\
\hline \multirow[t]{2}{*}{ Lymph node metastasis } & Negative & $21(35.6)$ & $106(23.7)$ & 0.05 \\
\hline & Positive & $38(64.4)$ & $342(76.3)$ & \\
\hline \multirow[t]{2}{*}{ Stage } & Early & $21(37.5)$ & $127(31.2)$ & 0.35 \\
\hline & Advanced & $35(62.5)$ & $280(68.8)$ & \\
\hline
\end{tabular}



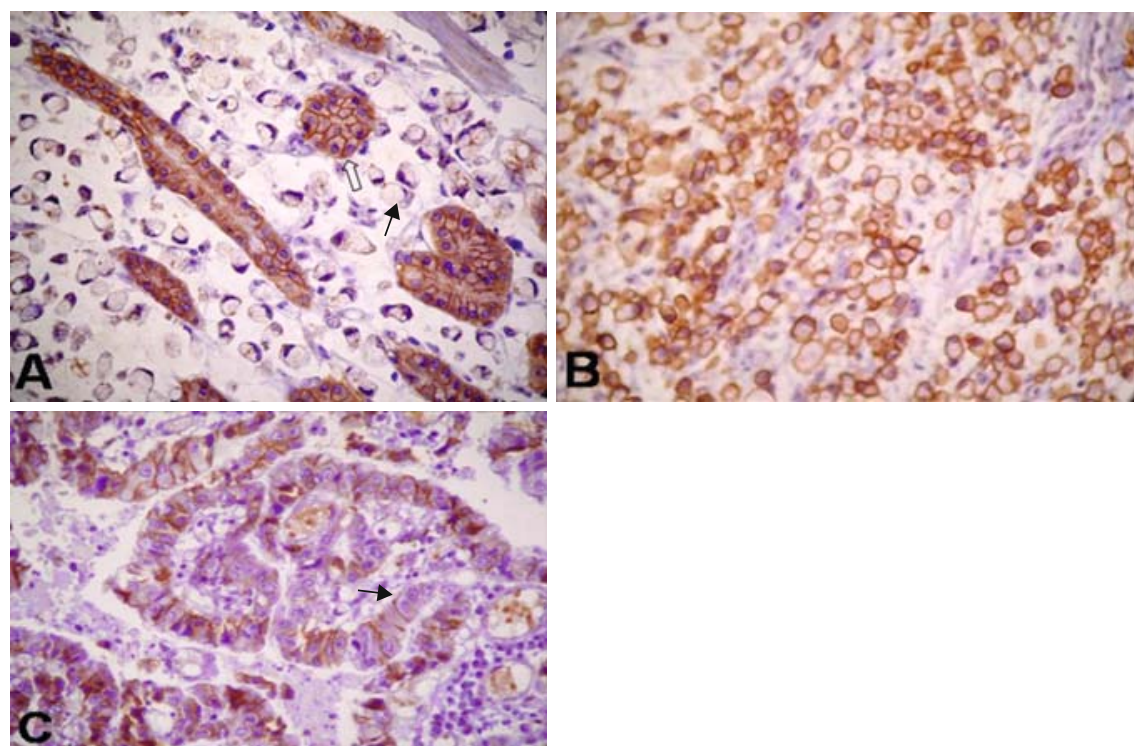

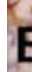
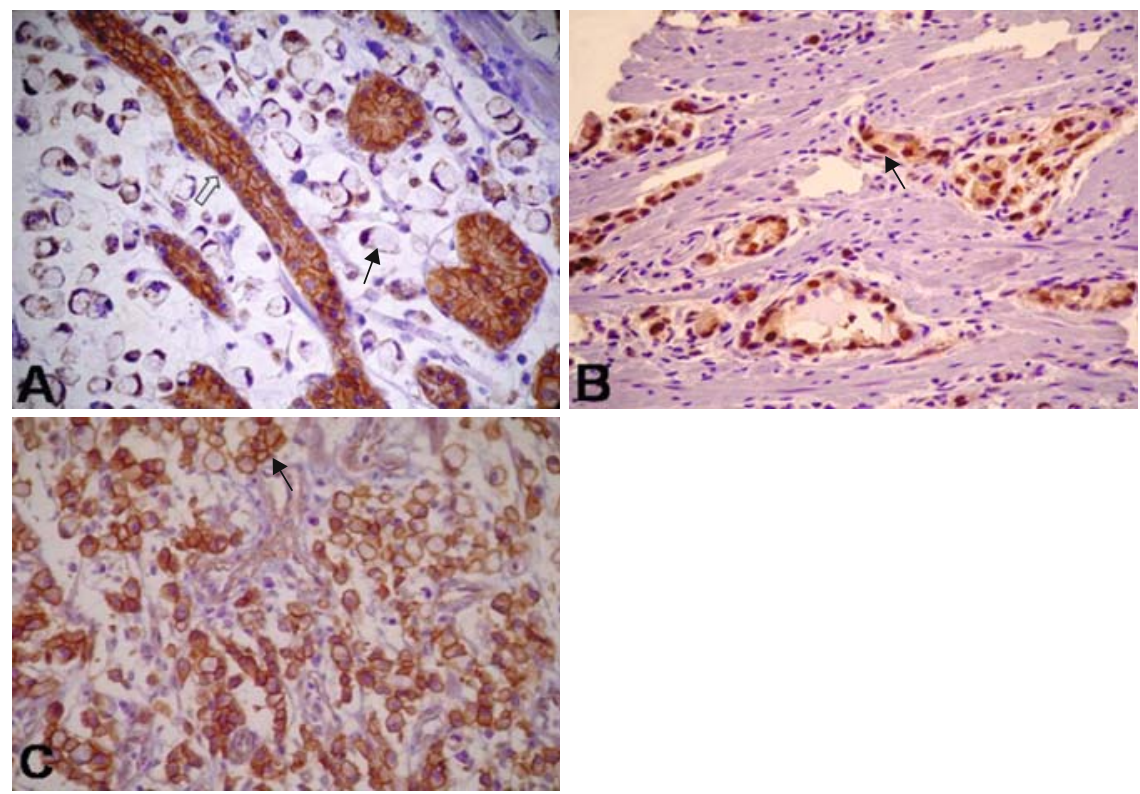

in the young group than in the older group $(P<0.01)$. Concerning $\beta$-catenin pattern expression, a similar situation occurred - the young group showed a higher preservation of membranous $\beta$-catenin expression $(P<$ 0.01 ). Comparison of the expression rates of each mucin in the carcinomas of the young and older patients showed that positivity for MUC2, MUC5AC, and MUC6 was higher in young patients with gastric carcinoma when compared with the older group $(P<0.01)$. No significant difference was seen between the positivity rates for MUC1 in the two groups (see Fig. 3A-H for the mucin expression patterns).

Follow-up ranged from 1 day to 177.5 months, with a mean follow-up of 20 months. When the survival analysis was restricted to the young patient group, only the
Fig. 1A-C. Representative immunohistochemical staining for E-cadherin in gastric cancer. A Diffuse-type gastric tumor displaying loss of membranous E-cadherin pattern expression (black arrow). Preserved membranous staining can be seen in adjacent normal glands (white arrow). B Diffuse-type gastric cancer with preserved membranous expression. C Intestinal-type gastric tumor with partial loss of membranous expression (black arrow). $\times 400$

Fig. 2A-C. Representative immunohistochemical staining for $\beta$-catenin in gastric cancer. A Loss of $\beta$-catenin in diffusetype gastric cancer (black arrow) compared with preserved membranous expression in normal glands (white arrow). B Nuclear staining with cytoplasmic distribution of $\beta$-catenin (black arrow) in neoplastic cells. C Diffuse-type tumor showing preserved membranous expression of $\beta$-catenin (black arrow). $\times 400$ stage persisted as a prognostic factor. However, univariate analysis of survival for all patients (Table 3 ) showed that patients with proximal tumor location, larger tumor size $(>5 \mathrm{~cm})$, lymph node metastasis, advanced-stage disease (all $P<0.01)$, and MUC6 negativity $(P=0.01)$ had a worse survival rate, as seen in Fig. 4. Sex, histological tumor type, and the expression patterns of E-cadherin, $\beta$-catenin, MUC1, MUC2, and MUC5AC were not significant prognostic factors for patients with gastric carcinomas $(P>0.05)$. Of interest, the young patients with gastric carcinoma had a better 5 -year survival rate than the older patients $(P=0.02)$ according to the univariate analysis, as seen in Fig. 4 (the age graphic). But multivariate analysis (Table 4) confirmed that only the stage of disease, tumor location, and tumor 

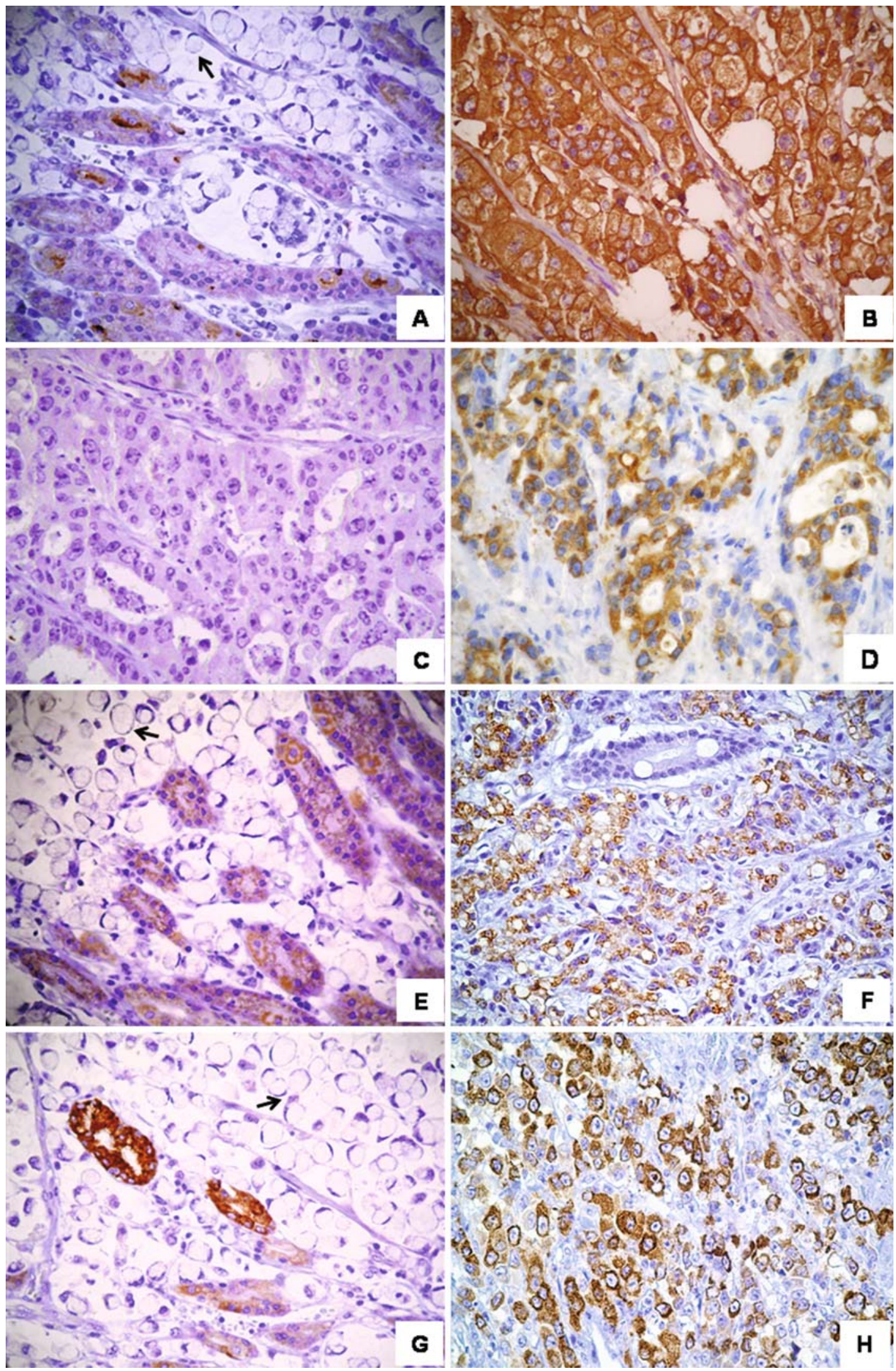

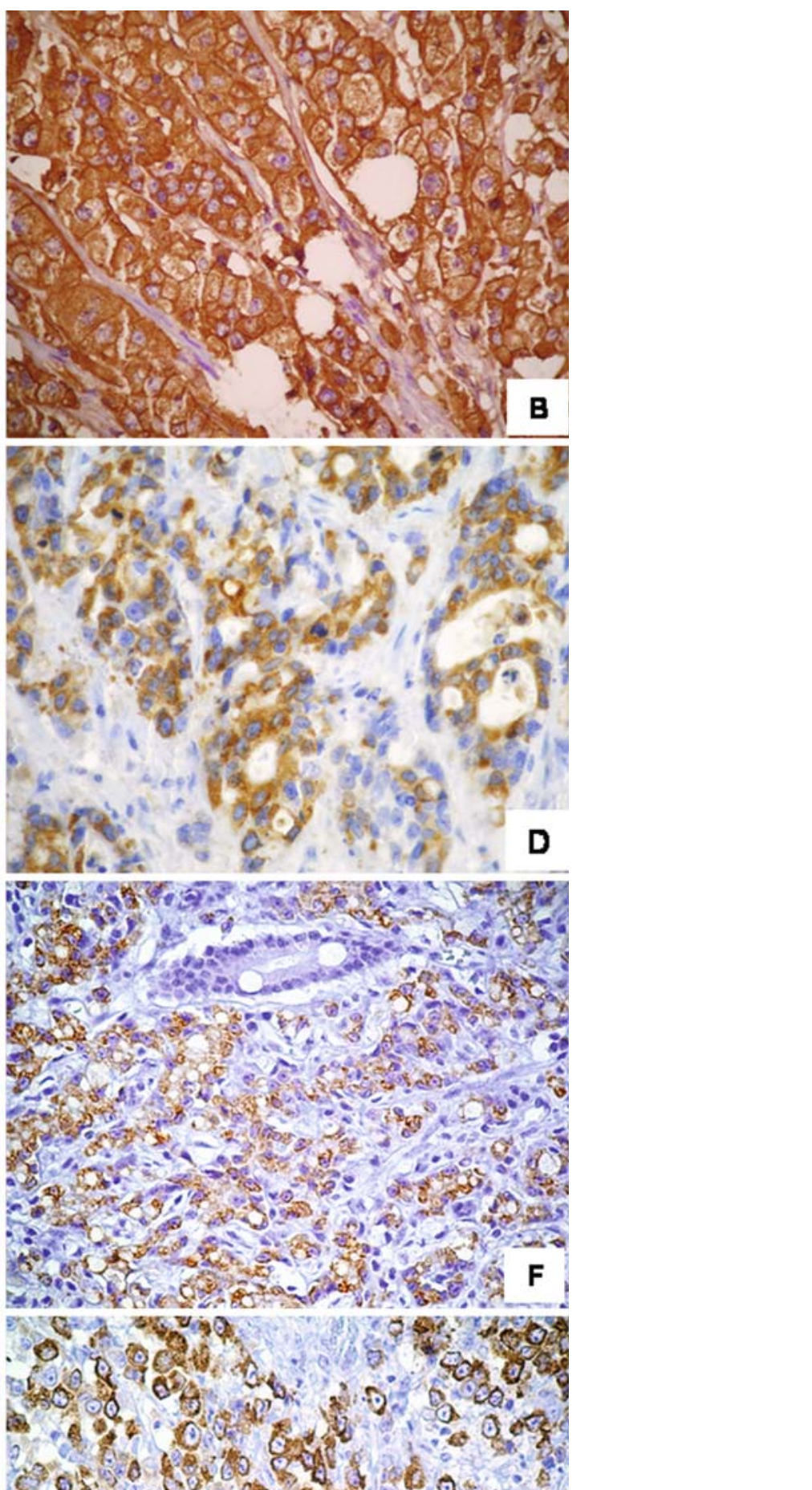

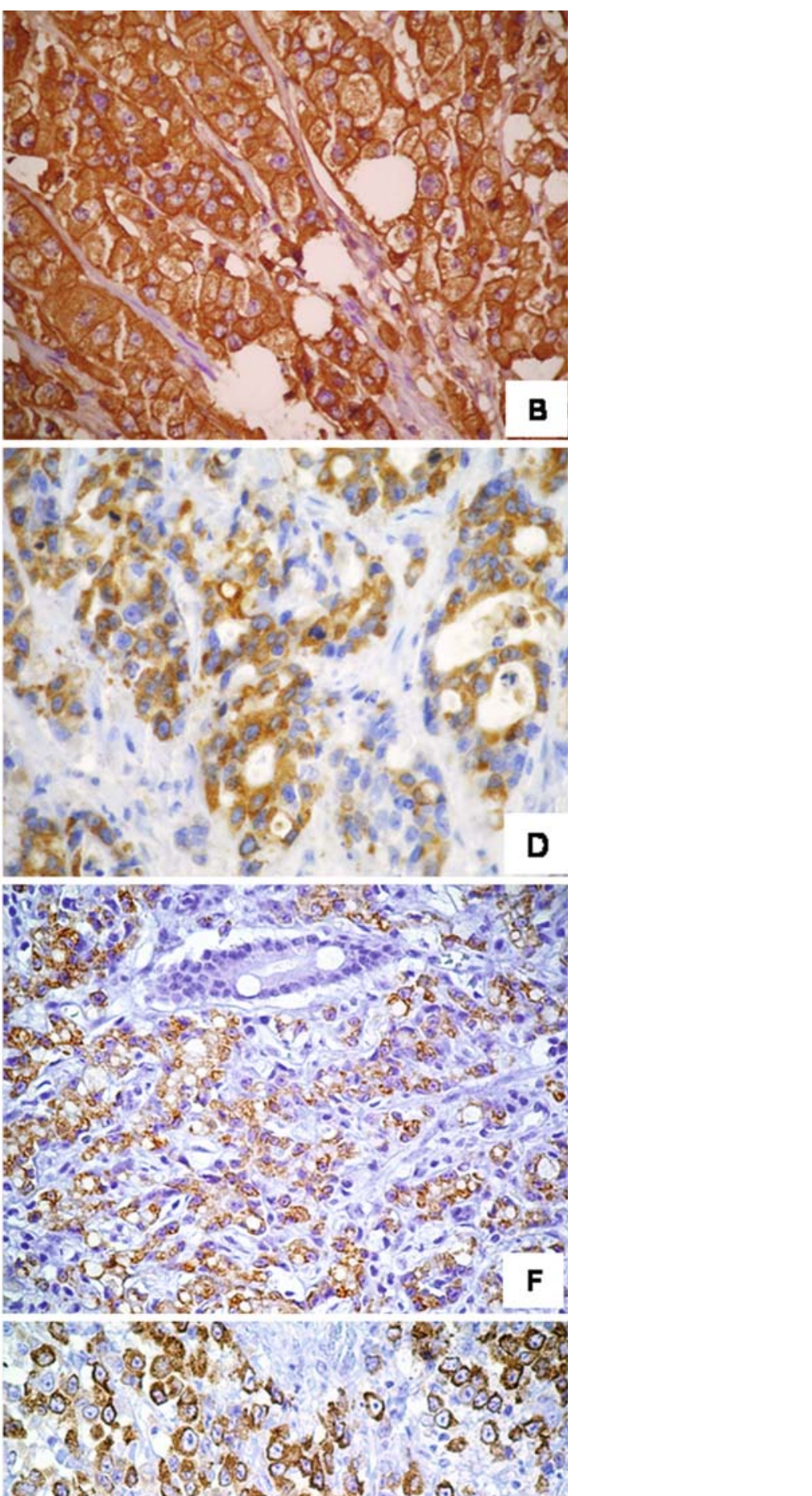

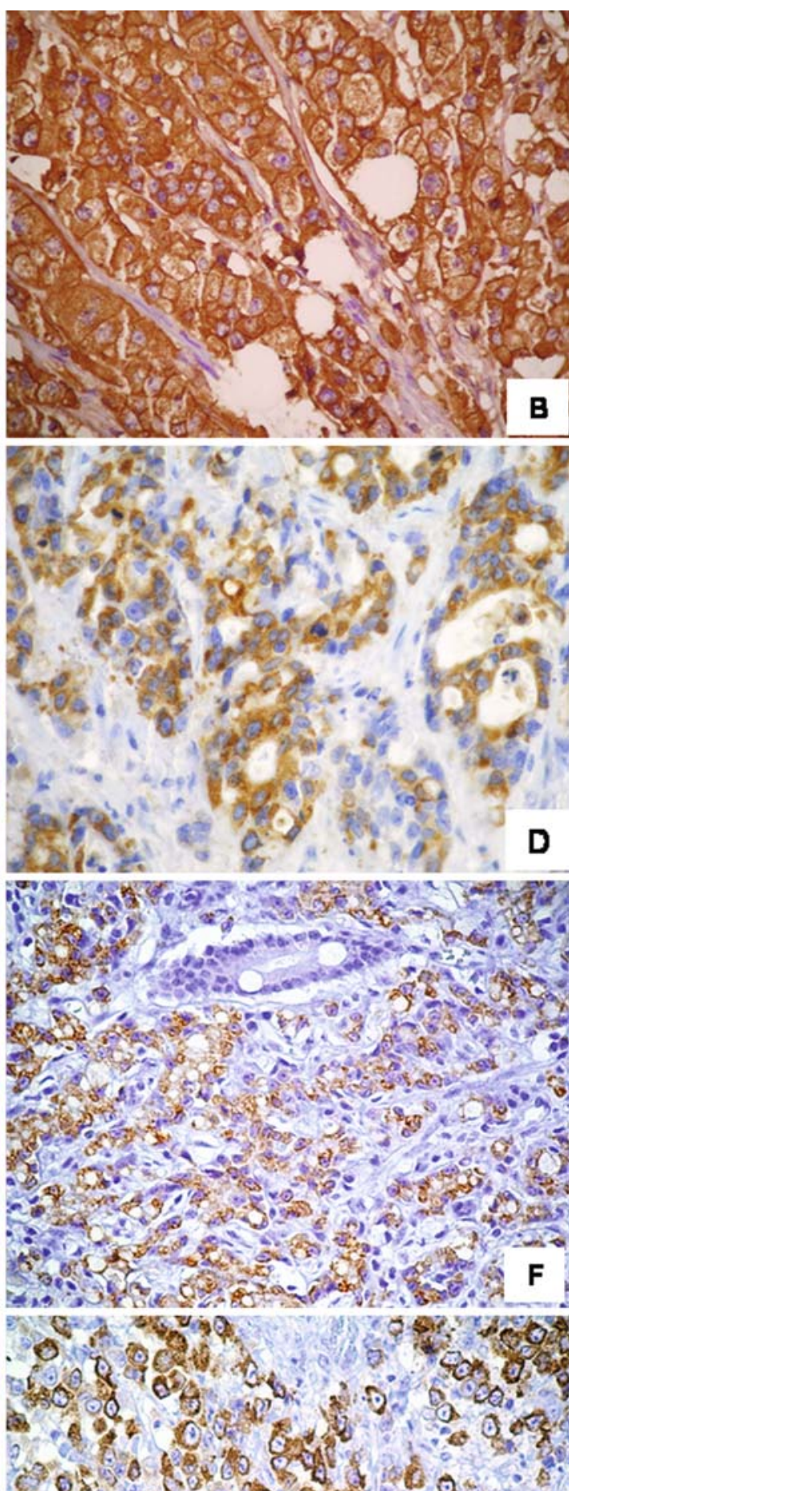

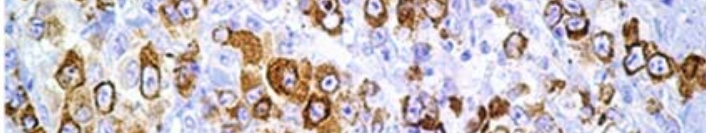

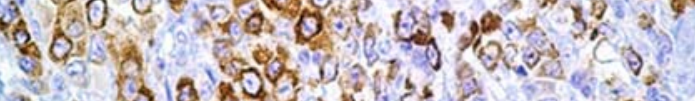

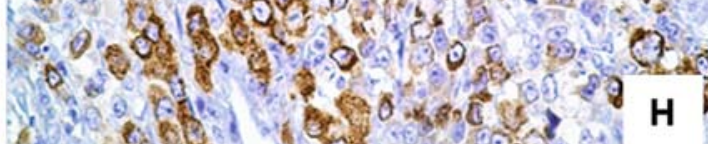

Fig. 3A-H. Representative immunohistochemical staining for mucins in gastric cancer: A/B, MUC1; C/D, MUC2; E/F, MUC5AC; G/H, MUC6. Panels on the left (A, C, E, G) represent negative staining (arrows, neoplastic cells showing negativity), and panels on the right $(\mathbf{B}, \mathbf{D}, \mathbf{F}, \mathbf{H})$ represent positivity. $\times 400$ 
Table 2. Comparison of molecular biomarker expression patterns between young and older patients with gastric carcinoma

\begin{tabular}{|c|c|c|c|c|}
\hline Variable & Category & $\leq 40$ Years $n=62(\%)$ & $>40$ Years $n=453(\%)$ & $P$ value \\
\hline \multirow[t]{2}{*}{ E-cadherin } & Altered & $35(57.4)$ & $322(74.9)$ & \multirow[t]{2}{*}{$<0.01$} \\
\hline & Membranous & $26(42.6)$ & $108(25.1)$ & \\
\hline \multirow[t]{2}{*}{$\beta$-Catenin } & Altered & $41(67.2)$ & $404(94.0)$ & \multirow[t]{2}{*}{$<0.01$} \\
\hline & Membranous & $20(32.8)$ & $26(6.0)$ & \\
\hline \multirow[t]{2}{*}{ MUC1 } & Negative & $45(75.0)$ & $346(82.2)$ & \multirow[t]{2}{*}{0.18} \\
\hline & Positive & $15(25.0)$ & $75(17.8)$ & \\
\hline \multirow[t]{2}{*}{ MUC2 } & Negative & $32(52.5)$ & $389(89.6)$ & \multirow[t]{2}{*}{$<0.01$} \\
\hline & Positive & $29(47.5)$ & $45(10.4)$ & \\
\hline \multirow[t]{2}{*}{ MUC5AC } & Negative & $19(31.7)$ & $349(80.4)$ & \multirow[t]{2}{*}{$<0.01$} \\
\hline & Positive & $41(68.3)$ & $85(19.6)$ & \\
\hline \multirow[t]{2}{*}{ MUC6 } & Negative & $35(61.4)$ & 425 (98.6) & \multirow[t]{2}{*}{$<0.01$} \\
\hline & Positive & $22(38.6)$ & $6(1.4)$ & \\
\hline
\end{tabular}

Table 3. Five-year overall survival rates according to clinicopathological and molecular biomarker expression in young and older patients with gastric carcinoma

\begin{tabular}{|c|c|c|c|c|}
\hline Variables & Category & $n$ & $\begin{array}{l}\text { 5-Year survival } \\
\text { rate }(\%)\end{array}$ & $P$ value \\
\hline \multirow[t]{2}{*}{ Age } & $\leq 40$ Years & 62 & 45.5 & 0.02 \\
\hline & $>40$ Years & 453 & 30.9 & \\
\hline \multirow[t]{2}{*}{ Sex } & M & 326 & 30.8 & 0.49 \\
\hline & $\mathrm{F}$ & 188 & 35.3 & \\
\hline \multirow[t]{2}{*}{ Tumor location } & Proximal & 76 & 21.6 & $<0.01$ \\
\hline & Distal & 435 & 34.5 & \\
\hline \multirow[t]{2}{*}{ Tumor size } & $\leq 5 \mathrm{~cm}$ & 209 & 45.5 & $<0.01$ \\
\hline & $>5 \mathrm{~cm}$ & 286 & 24.8 & \\
\hline \multirow[t]{3}{*}{ Histological type } & Intestinal & 244 & 33.3 & 0.94 \\
\hline & Diffuse & 182 & 34.3 & \\
\hline & Mixed/unclassified & 88 & 26.4 & \\
\hline \multirow[t]{2}{*}{ Lymph node metastasis } & Negative & 127 & 65.1 & $<0.01$ \\
\hline & Positive & 379 & 22.4 & \\
\hline \multirow[t]{2}{*}{ Stage } & Early & 148 & 65.9 & $<0.01$ \\
\hline & Advanced & 314 & 19.6 & \\
\hline \multirow{2}{*}{ E-cadherin } & Altered & 357 & 32.2 & 0.88 \\
\hline & Membranous & 133 & 29.5 & \\
\hline \multirow[t]{2}{*}{$\beta$-Catenin } & Altered & 445 & 31.8 & 0.98 \\
\hline & Membranous & 45 & 30.7 & \\
\hline \multirow[t]{2}{*}{ MUC1 } & Negative & 391 & 32.3 & 0.10 \\
\hline & Positive & 89 & 25.2 & \\
\hline \multirow[t]{2}{*}{ MUC2 } & Negative & 421 & 32.2 & 0.87 \\
\hline & Positive & 73 & 29.8 & \\
\hline \multirow[t]{2}{*}{ MUC5AC } & Negative & 368 & 30.3 & 0.20 \\
\hline & Positive & 125 & 34.6 & \\
\hline \multirow[t]{2}{*}{ MUC6 } & Negative & 460 & 30.5 & 0.01 \\
\hline & Positive & 27 & 57.4 & \\
\hline
\end{tabular}

size were independent risk factors for death. This analysis also showed that age itself was not an independent prognostic survival factor for patients with gastric cancer.

\section{Discussion}

There are controversies about whether gastric cancer in young patients differs in any way from gastric cancer in older patients. Young patients with gastric cancer are believed to have more aggressive disease and a poorer prognosis than older patients [7]. A comparative study from Japan demonstrated different features of gastric cancer in patients younger than 40 years compared with those in patients older than 70 years. In patients older than 70 years, tumors were smaller and less infiltrative, and differentiated lesions were more common in comparison to findings in the patients younger than 40 years [38]. 

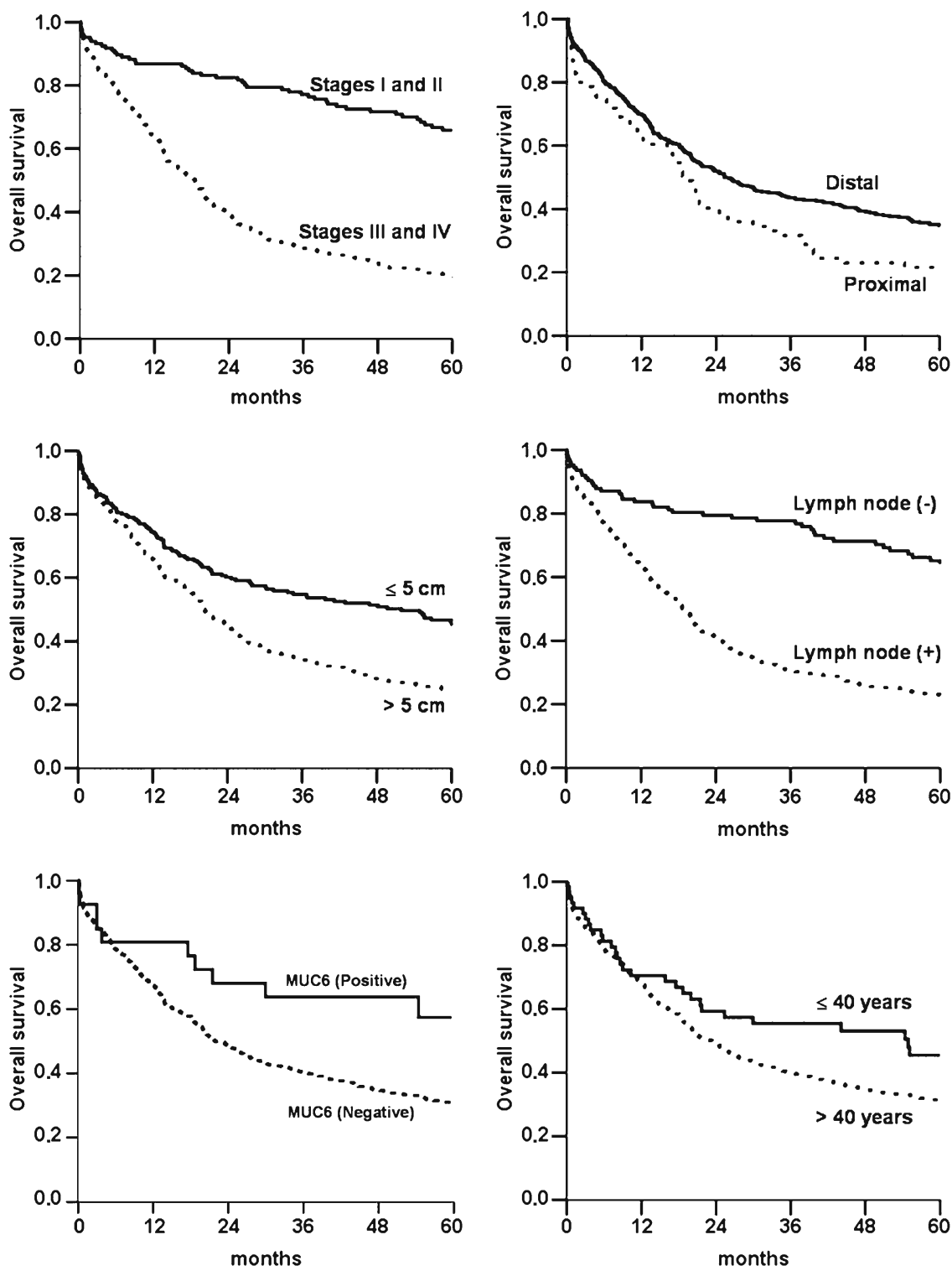

Fig. 4. Five-year overall survival according to the stage $(P<0.01)$, location of the disease $(P<0.01)$, tumor size $(P<0.01)$, lymph node status $(P<0.01)$, MUC6 expression $(P=0.01)$, and age $(P=0.02)$

Table 4. Independent risk factors for death in patients with gastric carcinoma identified in the Cox proportional hazards model (adjusted for age)

\begin{tabular}{|c|c|c|c|c|}
\hline Variables & Category & HR & $95 \% \mathrm{CI}$ & $P$ value \\
\hline Stage & Early & 1 & Ref. & $<0.01$ \\
\hline & Advanced & 3.5 & $2.6-4.7$ & \\
\hline Tumor location & $\begin{array}{l}\text { Distal } \\
\text { Proximal }\end{array}$ & 1 & Ref. & 0.03 \\
\hline Tumor size & $\begin{array}{l}\leq 5 \mathrm{~cm} \\
>5 \mathrm{~cm}\end{array}$ & $\begin{array}{l}1 \\
1.4\end{array}$ & $\begin{array}{l}\text { Ref. } \\
1.1-1.7\end{array}$ & 0.01 \\
\hline Age & $\begin{array}{l}\leq 40 \text { Years } \\
>40 \text { Years }\end{array}$ & $\begin{array}{l}1 \\
1.2\end{array}$ & $\begin{array}{l}\text { Ref. } \\
0.8-1.8\end{array}$ & 0.39 \\
\hline
\end{tabular}

CI, confidence interval; HR, hazard ratio

In our series, there was a male predominance in both age groups, and there was no significant difference in male-female distribution between the young and older patients, as reported previously [12]. In regard to the tumor location, the frequency of tumors located in proximal and distal regions in our study was similar in the young and older patients $(P=0.96)$, although some authors have found that the upper third of 
the stomach was more frequently involved in young patients [11]. We found that young patients were more likely to present with smaller tumors $(\leq 5 \mathrm{~cm})$ than older patients, but the difference did not reach statistical significance.

Diffuse histology has consistently been shown to be associated with a young age at diagnosis $[3,11]$. In accordance with previous reports, we found that significantly more young patients had diffuse histology than intestinal or mixed histology, while gastric carcinoma in the older group was usually the intestinal type $(P<$ $0.01)$. This correlation between age and intestinal type, which has been associated with precursor changes described by the multistep carcinogenesis model as a sequential chain of events characterized as chronic gastritis, atrophy, intestinal metaplasia, dysplasia, and carcinoma [39], involves environmental factors. However, the predominance of diffuse-type tumors in young patients suggests an association with genotypic events involving E-cadherin gene mutation in the gastric neoplastic process.

In our series, $75 \%$ of all patients presented with nodepositive disease. It was expected that as the young group presented with a higher frequency of diffuse-type tumor, this also could represent an increased rate of isolated cells infiltrating the gastric wall and a higher frequency of lymph node metastasis; however, there were no significant differences in lymph node metastasis between the two groups $(P=0.05)$ [11]. In our casuistic, approximately $68 \%$ of all patients presented with advanced tumor stage at diagnosis, and no significant differences were found between the two groups in the frequency of early and advanced stage.

Regarding the tested markers, we observed that alterations in E-cadherin/ $\beta$-catenin adhesion complex expression occured in a considerable proportion of gastric carcinomas in both groups of patients $(\leq 40$ years vs $>40$ years). The E-cadherin expression pattern has been associated with histological tumor type [40, 41] and it has been suggested that loss of E-cadherin is a crucial defect in diffuse-type tumors, and this could explain the observed phenotype of noncohesive cells [42]. According to this correlation between histological type and cadherin-catenin adhesion system expression, it was expected that, as the young group presented with a higher proportion of diffusetype tumors, this group could also present with a higher frequency of alterations in the cadherin/catenin complex compared to the older group. However, in our patients, the young group presented with a significantly higher percentage of the membranous expression pattern of the adhesion system complex when compared to findings in the older group $(42.6 \%$ vs $25.1 \%$ for E-cadherin, and $32.8 \%$ vs $6.0 \%$ for $\beta$-catenin; both $P<0.01)$.
We observed some cases of diffuse-type gastric carcinomas displaying $E$-cadherin and $\beta$-catenin membranous expression (Figs. 1B and 2C), and some intestinal-type tumors lacking the expression of these markers (Fig. 1C). These findings strongly suggest that, in some cases, the presence of E-cadherin, as revealed by immunohistochemistry, might not indicate that E-cadherin is necessarily functional. We might consider that E-cadherin interacts with other proteins, such as APC, c-erbB-2, and p120 (not included in this study), and that alterations in these proteins interacting with the cadherincatenin system may affect its adhesive function, despite the expression of E-cadherin and $\beta$-catenin being normal [40, 43-45]. Another possibility might be a functional defect of E-cadherin with normal immunohistochemical expression, as has been shown to occur in diffuse-type gastric cancer due to exon skipping in the E-cadherin gene [46]. Nuclear expression of $\beta$-catenin was observed in both groups, but the molecular mechanisms leading to the activation of the $\mathrm{Wnt} / \mathrm{\beta}$-catenin signaling pathway still have to be elucidated in our series. Some authors have reported correlations between the E-cadherin expression pattern and prognosis [47-49], in contrast to the reports of others $[40,50]$. According to our data, no correlations were found between E-cadherin and $\beta$ catenin expression and prognosis.

Several groups have studied the correlation between MUC1 gene expression, clinicopathological features, and the prognoses of patients with breast, pancreatic, and colon cancers [51-53]. However, there were conflicting results regarding the prognostic value of MUC1, in part because of the use of different antibodies recognizing different glycoforms or different core peptides of MUC1 mucin, both of characteristics which can be modified during carcinogenesis [54]. In the present study, we did not find that MUC1 had a prognostic role in gastric cancer patients, a finding which is consistent with the results reported by Reis et al. [55], but different from those reported by Utsunomiya et al. [56] and other authors [57], who found that positive MUC1 expression was a marker of malignancy in gastric cancer.

It has been suggested that positivity for the gastric mucins (MUC5AC and MUC6) normally expressed in normal gastric epithelium, and/or positivity for intestinal mucin MUC2 is associated with a better prognosis in gastric adenocarcinoma [56, 58, 59]. Although we did not find any significant correlation between mucin expression and prognosis in our series, we observed that the positive expression of gastric mucins (MUC5AC and MUC6) and the intestinal mucin MUC2 was significantly more frequent in the young than in the older patients.

Some authors have suggested that MUC2 expression in tumors was correlated with lower levels of invasion and lymph node metastasis in gastric carcinomas [56]. 
Therefore, MUC2 expression may be inversely correlated with tumor aggressiveness in gastric carcinomas. Moreover, MUC2 expression has been related more specifically to the mucinous subtype of the WHO classification, which was included in the diffuse-subtype group of Lauren's classification in our series. In our series, we observed a higher percentage of MUC2 positivity in the young patient group, and we can associate this result as being due to the higher rate of diffuse-type tumor in this group.

In our casuistic, only $5.7 \%$ of all patients presented with MUC6 positivity. Other studies reported similar results $[33,60,61]$; in contrast, however, other studies reported higher percentages for positivity [33]. The different results regarding the prognostic value of mucins may reflect the use of different antibodies and also the score chosen for the mucin antigens (at least $10 \%$ of neoplastic cells stained). Our univariate analysis indicated that MUC6 positive expression was associated with a significantly better survival rate, but the prognostic value of this marker was not confirmed in the multivariate analysis.

We observed that alterations in E-cadherin/ $\beta$-catenin adhesion complex expression and in the mucin (MUC2, MUC5AC and MUC6) expression occurred in a high percentage of gastric carcinomas in both groups of patients ( $\leq 40$ years vs $>40$ years), but the older group displayed significantly higher percentages of altered expression patterns. Considering our findings, gastric carcinomas in young patients appear to have characteristics that are different from those of gastric carcinomas occurring at a later age $[13,15]$; the markers addressed in this study do not appear to play a predominant role in gastric carcinomas in young patients, considering that these patients displayed higher preservation of marker expression, and in addition, a better survival rate. Despite the significant differences between the groups, the markers we tested were not significant prognostic factors for patients with gastric carcinomas.

In our casuistic, when the overall survival analysis was restricted to the young patient group, none of the other factors except for the tumor stage, were found to have a prognostic significance. The survival analysis for all patients was influenced by age, tumor stage, tumor location, tumor size, and lymph node involvement, as shown by the univariate analysis. However, the multivariate analysis indicated that age was not an independent factor for survival, in agreement with other studies $[12,62]$. The pathological stage of gastric cancer remains the most important determinant of the prognosis.

The present study showed that the prognosis of gastric carcinoma is nearly always poor for both young and older groups of patients. Although only tumor stage persisted as an independent prognostic factor independent of the age of the patients, and age itself was not a prognostic factor, in our series there were significant differences regarding clinicopathological parameters and marker expression patterns between the young and older patients. The young patients had a better survival rate and a higher percentage of marker expression preservation. Our findings support the hypothesis that young patients develop carcinomas that have a different genetic pathway compared with that of tumors occurring at a later age. We suggest further investigations of these young patients to provide clues as to why they are different and to identify subgroups that would benefit from screening and the detection of early disease. Further studies should also assess the prognostic relevance of the markers to specific patient groups.

Acknowledgments Financial support was provided by Fundação de Amparo à Pesquisa do Estado de São Paulo (FAPESP/CEPID) and Coordenação de Aperfeiçoamento de Pessoal de Nível Superior (CAPES). The authors thank Dr. Jeremy A. Squire for his critical reading of the manuscript and Sueli Nonogaki, Carlos F. Nascimento, and Severino S. Ferreira for their expert technical assistance.

\section{References}

1. Mitsudomi T, Matsusaka T, Wakasugi K, Takenaka M, Kume K, Fujinaga Y, et al. A clinicopathological study of gastric cancer with special reference to age of the patients: an analysis of 1630 cases. World J Surg 1989;13:225-30.

2. Sanchez-Bueno F, Garcia-Marcilla JA, Perez-Flores D, PerezAbad JM, Vicente R, Aranda F, et al. Prognostic factors in a series of 297 patients with gastric adenocarcinoma undergoing surgical resection. Br J Surg 1998;85:255-60.

3. Theuer CP, de Virgilio C, Keese G, French S, Arnell T, Tolmos $\mathrm{J}$, et al. Gastric adenocarcinoma in patients 40 years of age or younger. Am J Surg 1996;172:473-6.

4. Eguchi T, Takahashi Y, Yamagata M, Kasahara M, Fujii M. Gastric Cancer in Young Patients. J Am Coll Surg 1999;188: 22-6.

5. Nakamura T, Yao T, Niho Y, Tsuneyoshi M. A Clinicopathological Study in Young Patients With Gastric Carcinoma. J Surg Oncol 1999;71:214-9.

6. Matley PJ, Dent DM, Madden MV, Price SK. Gastric Carcinoma in Young Adults. Ann Surg 1988;208:593-6.

7. Tso PL, Bringaze WL, III, Dauterive AH, Correa P, Cohn I, Jr. Gastric Carcinoma in the Young. Cancer 1987;59:1362-5.

8. Rugge M, Busatto G, Cassaro M, Shiao YH, Russo V, Leandro G, et al. Patients Younger Than 40 Years With Gastric Carcinoma: Helicobacter pylori Genotype and Associated Gastritis Phenotype. Cancer 1999;85:2506-11.

9. Fuchs CS, Mayer RJ. Gastric Carcinoma. N Engl J Med 1995; 333:32-41.

10. Wanebo HJ, Kennedy BJ, Chmiel J, Steele G, Jr, Winchester D, Osteen R. Cancer of the Stomach. A Patient Care Study by the American College of Surgeons. Ann Surg 1993;218:583-92.

11. Kim DY, Joo JK, Ryu SY, Park YK, Kim YJ, Kim SK. Clinicopathologic Characteristics of Gastric Carcinoma in Elderly Patients: a Comparison With Young Patients. World J Gastroenterol 2005;11:22-6. 
12. Medina-Franco H, Heslin MJ, Cortes-Gonzalez R. Clinicopathological Characteristics of Gastric Carcinoma in Young and Elderly Patients: a Comparative Study. Ann Surg Oncol 2000;7:5159.

13. Carvalho R, Milne AN, van Rees BP, Caspers E, Cirnes L, Figueiredo C, et al. Early-Onset Gastric Carcinomas Display Molecular Characteristics Distinct From Gastric Carcinomas Occurring at a Later Age. J Pathol 2004;204:75-83.

14. Buffart TE, Carvalho B, Hopmans E, Brehm V, Kranenbarg EK, Schaaij-Visser TB, et al. Gastric Cancers in Young and Elderly Patients Show Different Genomic Profiles. J Pathol 2007;211: 45-51.

15. Milne AN, Carvalho R, Morsink FM, Musler AR, de Leng WW, Ristimaki A, Offerhaus GJ. Early-Onset Gastric Cancers Have a Different Molecular Expression Profile Than Conventional Gastric Cancers. Mod Pathol 2006;19:564-72.

16. Meireles SI, Cristo EB, Carvalho AF, Hirata R, Jr, Pelosof A, Gomes LI, et al. Molecular Classifiers for Gastric Cancer and Nonmalignant Diseases of the Gastric Mucosa. Cancer Res 2004:64:1255-65.

17. Suriano G, Mulholland D, de Wever O, Ferreira P, Mateus AR, Bruyneel E, et al. The Intracellular E-Cadherin Germline Mutation V832 M Lacks the Ability to Mediate Cell-Cell Adhesion and to Suppress Invasion. Oncogene 2003;22:5716-9.

18. Takeichi M. Cadherin Cell Adhesion Receptors As a Morphogenetic Regulator. Science 1991;251:1451-5.

19. Behrens J, von Kries JP, Kuhl M, Bruhn L, Wedlich D, Grosschedl R, Birchmeier W. Functional Interaction of Beta-Catenin With the Transcription Factor LEF-1. Nature 1996;382:638-42.

20. Nabais S, Machado JC, Lopes C, Seruca R, Carneiro F, Sobrinho-Simoes M. Patterns of Beta-Catenin Expression in Gastric Carcinoma: Clinicopathological Relevance and Mutation Analysis. Int J Surg Pathol 2003;11:1-9.

21. Tanaka M, Kitajima Y, Edakuni G, Sato S, Miyazaki K. Abnormal Expression of E-Cadherin and Beta-Catenin May Be a Molecular Marker of Submucosal Invasion and Lymph Node Metastasis in Early Gastric Cancer. Br J Surg 2002;89:23644.

22. Pierceall WE, Woodard AS, Morrow JS, Rimm D, Fearon ER. Frequent Alterations in E-Cadherin and Alpha- and Beta-Catenin Expression in Human Breast Cancer Cell Lines. Oncogene 1995;11:1319-26.

23. Huntsman DG, Carneiro F, Lewis FR, MacLeod PM, Hayashi A, Monaghan KG, et al. Early Gastric Cancer in Young, Asymptomatic Carriers of Germ-Line E-Cadherin Mutations. N Engl J Med 2001;344:1904-9.

24. Gayther SA, Gorringe KL, Ramus SJ, Huntsman D, Roviello F, Grehan N, et al. Identification of Germ-Line E-Cadherin Mutations in Gastric Cancer Families of European Origin. Cancer Res 1998;58:4086-9.

25. Guilford P, Hopkins J, Harraway J, McLeod M, McLeod N, Harawira P, et al. E. E-Cadherin Germline Mutations in Familial Gastric Cancer. Nature 1998;392:402-5.

26. Richards FM, McKee SA, Rajpar MH, Cole TR, Evans DG, Jankowski JA, et al. Germline E-Cadherin Gene (CDH1) Mutations Predispose to Familial Gastric Cancer and Colorectal Cancer. Hum Mol Genet 1999;8:607-10.

27. Guilford PJ, Hopkins JB, Grady WM, Markowitz SD, Willis J, Lynch H, et al. E-Cadherin Germline Mutations Define an Inherited Cancer Syndrome Dominated by Diffuse Gastric Cancer. Hum Mutat 1999;14:249-55.

28. Williams SJ, Wreschner DH, Tran M, Eyre HJ, Sutherland GR, McGuckin MA. Muc13, a Novel Human Cell Surface Mucin Expressed by Epithelial and Hemopoietic Cells. J Biol Chem 2001;276:18327-36.

29. Bresalier RS, Niv Y, Byrd JC, Duh QY, Toribara NW, Rockwell RW, et al. Mucin Production by Human Colonic Carcinoma Cells Correlates With Their Metastatic Potential in Animal Models of Colon Cancer Metastasis. J Clin Invest 1991;87:1037-45.
30. Majuri ML, Mattila P, Renkonen R. Recombinant E-SelectinProtein Mediates Tumor Cell Adhesion Via Sialyl-Le(a) and Sialyl-Le(x). Biochem Biophys Res Commun 1992;182: 1376-82.

31. Kuan SF, Byrd JC, Basbaum CB, Kim YS. Characterization of Quantitative Mucin Variants From a Human Colon Cancer Cell Line. Cancer Res 1987;47:5715-24.

32. Carrato C, Balague C, de Bolos C, Gonzalez E, Gambus G, Planas J, et al. Differential Apomucin Expression in Normal and Neoplastic Human Gastrointestinal Tissues. Gastroenterology 1994;107:160-72.

33. Ho SB, Shekels LL, Toribara NW, Kim YS, Lyftogt C, Cherwitz DL, et al. Mucin Gene Expression in Normal, Preneoplastic, and Neoplastic Human Gastric Epithelium. Cancer Res 1995;55: 2681-90.

34. Lauren P. The two histological main types of gastric carcinoma: diffuse and so-called intestinal-type carcinoma. an attempt at a histo-clinical classification. Acta Pathol Microbiol Scand 1965; 64:31-49.

35. Camp RL, Charette LA, Rimm DL. Validation of Tissue Microarray Technology in Breast Carcinoma. Lab Invest 2000;80: 1943-9.

36. Hoos A, Urist MJ, Stojadinovic A, Mastorides S, Dudas ME, Leung DH, et al. Validation of Tissue Microarrays for Immunohistochemical Profiling of Cancer Specimens Using the Example of Human Fibroblastic Tumors. Am J Pathol 2001;158:1245-51.

37. Ho SB, Niehans GA, Lyftogt C, Yan PS, Cherwitz DL, Gum ET, et al. Heterogeneity of Mucin Gene Expression in Normal and Neoplastic Tissues. Cancer Res 1993;53:641-51.

38. Maehara Y, Emi Y, Tomisaki S, Oshiro T, Kakeji Y, Ichiyoshi Y, et al. Age-Related Characteristics of Gastric Carcinoma in Young and Elderly Patients. Cancer 1996;77:1774-80.

39. Correa P, Chen VW. Gastric Cancer. Cancer Surv 1994;19-20: $55-76$.

40. Jawhari A, Jordan S, Poole S, Browne P, Pignatelli M, Farthing MJ. Abnormal Immunoreactivity of the E-Cadherin-Catenin Complex in Gastric Carcinoma: Relationship With Patient Survival. Gastroenterology 1997;112:46-54.

41. Joo YE, Rew JS, Choi SK, Bom HS, Park CS, Kim SJ. Expression of E-Cadherin and Catenins in Early Gastric Cancer. J Clin Gastroenterol 2002;35:35-42.

42. Machado JC, Soares P, Carneiro F, Rocha A, Beck S, Blin N, et al. E-Cadherin Gene Mutations Provide a Genetic Basis for the Phenotypic Divergence of Mixed Gastric Carcinomas. Lab Invest 1999;79:459-65.

43. Shimoyama Y, Hirohashi S. Expression of E- and P-Cadherin in Gastric Carcinomas. Cancer Res 1991;51:2185-92.

44. Jawhari AU, Noda M, Pignatelli M, Farthing M. Up-Regulated Cytoplasmic Expression, With Reduced Membranous Distribution, of the Src substrate P120 (Ctn) in Gastric Carcinoma. J Pathol 1999;189:180-5.

45. Zhou YN, Xu CP, Han B, Li M, Qiao L, Fang DC, et al. Expression of E-Cadherin and Beta-Catenin in Gastric Carcinoma and Its Correlation With the Clinicopathological Features and Patient Survival. World J Gastroenterol 2002;8:987-93.

46. Becker KF, Atkinson MJ, Reich U, Huang HH, Nekarda H, Siewert JR, et al. Exon Skipping in the E-Cadherin Gene Transcript in Metastatic Human Gastric Carcinomas. Hum Mol Genet 1993;2:803-4.

47. Gabbert HE, Mueller W, Schneiders A, Meier S, Moll R, Birchmeier W, et al. Prognostic Value of E-Cadherin Expression in 413 Gastric Carcinomas. Int J Cancer 1996;69:184-9.

48. Grabsch H, Takeno S, Noguchi T, Hommel G, Gabbert HE, Mueller W. Different Patterns of Beta-Catenin Expression in Gastric Carcinomas: Relationship With Clinicopathological Parameters and Prognostic Outcome. Histopathology 2001;39: $141-9$.

49. Chen HC, Chu RY, Hsu PN, Hsu PI, Lu JY, Lai KH, et al. Loss of E-Cadherin Expression Correlates With Poor Differentiation 
and Invasion into Adjacent Organs in Gastric Adenocarcinomas. Cancer Lett 2003;201:97-106.

50. Ramesh S, Nash J, McCulloch PG. Reduction in Membranous Expression of Beta-Catenin and Increased Cytoplasmic ECadherin Expression Predict Poor Survival in Gastric Cancer. Br J Cancer 1999;81:1392-7.

51. Rahn JJ, Dabbagh L, Pasdar M, Hugh JC. The Importance of MUC1 Cellular Localization in Patients With Breast Carcinoma: an Immunohistologic Study of 71 Patients and Review of the Literature. Cancer 2001;91:1973-82.

52. Nakamori S, Ota DM, Cleary KR, Shirotani K, Irimura T. MUC1 Mucin Expression As a Marker of Progression and Metastasis of Human Colorectal Carcinoma. Gastroenterology 1994;106: 353-61.

53. Terada T, Ohta T, Sasaki M, Nakanuma Y, Kim YS. Expression of MUC Apomucins in Normal Pancreas and Pancreatic Tumours. J Pathol 1996;180:160-5.

54. Kim YS, Gum J, Jr, Brockhausen I. Mucin Glycoproteins in Neoplasia. Glycoconj J 1996;13:693-707.

55. Reis CA, David L, Seixas M, Burchell J, Sobrinho-Simoes M. Expression of Fully and Under-Glycosylated Forms of MUC1 Mucin in Gastric Carcinoma. Int J Cancer 1998;79:402-10.

56. Utsunomiya T, Yonezawa S, Sakamoto H, Kitamura H, Hokita $\mathrm{S}$, Aiko T, et al. Expression of MUC1 and MUC2 Mucins in Gastric Carcinomas: Its Relationship With the Prognosis of the Patients. Clin Cancer Res 1998;4:2605-14.
57. Tanaka M, Kitajima Y, Sato S, Miyazaki K. Combined Evaluation of Mucin Antigen and E-Cadherin Expression May Help Select Patients With Gastric Cancer Suitable for Minimally Invasive Therapy. Br J Surg 2003;90:95-101.

58. Baldus SE, Zirbes TK, Engel S, Hanisch FG, Monig SP, Lorenzen $\mathrm{J}$, et al. Correlation of the Immunohistochemical Reactivity of Mucin Peptide Cores MUC1 and MUC2 With the Histopathological Subtype and Prognosis of Gastric Carcinomas. Int J Cancer 1998;79:133-8.

59. Baldus SE, Monig SP, Arkenau V, Hanisch FG, Schneider PM, Thiele J, et al. Correlation of MUC5AC Immunoreactivity With Histopathological Subtypes and Prognosis of Gastric Carcinoma. Ann Surg Oncol 2002;9:887-93.

60. Reis CA, David L, Carvalho F, Mandel U, de Bolos C, Mirgorodskaya E, et al. Immunohistochemical Study of the Expression of MUC6 Mucin and Co-Expression of Other Secreted Mucins (MUC5AC and MUC2) in Human Gastric Carcinomas. J Histochem Cytochem 2000;48:377-88.

61. Pinto-de-Sousa J, David L, Reis CA, Gomes R, Silva L, Pimenta A. Mucins MUC1, MUC2, MUC5AC and MUC6 Expression in the Evaluation of Differentiation and ClinicoBiological Behaviour of Gastric Carcinoma. Virchows Arch 2002; 440:304-10.

62. Kokkola A, Sipponen P. Gastric Carcinoma in Young Adults. Hepatogastroenterology 2001;48:1552-5. 